\title{
INFLUENCIA DEL CINE EN LA GENERACIÓN DEL 27
}

\author{
Flora Lobato ${ }^{1}$ \\ Escritora y Docente en España \\ España
}

Recibido: 19 de marzo, 2008 • Aprobado: 22 de abril, 2008

\begin{abstract}
Resumen: Este artículo se centra en la influencia que el cine ejerció en la literatura. La aparición del cinematógrafo supuso una revolución en lo cultural; y el mundo de la imagen vino a sumarse a otras artes milenarias, como la pintura y la literatura, las cuales habían servido al hombre para expresar ideas y sentimientos. El cine se considera una rama más de las vanguardias, y, así, el genio creativo de nuestros poetas de la Generación del 27 se vio fructificado, accediendo a territorios antes no explorados por ellos, con lo que sus imágenes y metáforas sobrepasaron los límites conocidos y se adentraron en un universo nuevo, marcado por lógicas de carácter más aperturista.
\end{abstract}

Palabras clave: Literatura, cine, poesía, Generación del 27.

\begin{abstract}
This article focuses on the influence cinema has had on literature, since as we have seen, the arrival of filmmakers led to a cultural revolution. The world of cinema was joined to other traditional arts, suchs as painting and literature, which man had already used to express his ideas and feelings. Cinema forms part of the new 20th century trends, influencing the poets of creating new imagery and metaphors which so greatly enhanced their work.
\end{abstract}

Key words: Literature, cinema, poetry, The 1927 Generation.

\section{Introducción}

El cine ha tenido una gran trascendencia en la literatura española, el que, si bien, al principio contó con cierto rechazo, por parte de los autores de la Generación del 98, por el contrario, los poetas del 27 se sintieron fascinados por el mundo de la imagen, pues gracias a ella, lograron captar la realidad en un sentido mucho más amplio y descubrir áreas ignotas de ella, hasta entonces, lo que revirtió en su creación poética. El cine actuó en ellos a modo de fuente en la que saciaban su sed, pues representaba la renovación, el dinamismo, la modernidad, en el sentido primigenio del vocablo, y, una vez asimilados dichos conceptos, lo

Licenciada en Filología Hispánica y Doctora por la Universidad de Salamanca. Su actividad principal es la enseñanza. alihalabi@teleline.es 
extraído del cine lo vierten en la literatura. Se da una interrelación entre las dos manifestaciones artísticas: el cinematógrafo ayudó la los poetas de la Generación del 27 a expandir su imaginación, y ellos lo vuelcan en una poesía más profunda, más rica en imágenes y recursos.

Se siguen distintas líneas de investigación que nos llevan a concretar el número de poetas más impactados por la aparición cinematográfica, así como a contemplar la distinta intensidad con que el cine actuó en unos y otros.

\section{Poetas marcados por el cine}

Las opiniones respecto al tema que nos ocupa, aunque no son absolutamente idénticas, están muy cercanas. Gutiérrez Carbajo (1993) considera que en la Generación del 27 no sólo encontramos influencias del cine en Alberti o Lorca, sino, también, en otros poetas, aunque no tan ligados al medio, como Salinas, Guillén, Aleixandre y Diego. Morris (1993) va más allá, y de sus palabras deducimos que el arte cinematográfico no tuvo las mismas consecuencias para la totalidad de los poetas, pues hubo algunos que recibieron su impacto de un modo superficial, mientras que otros lo acusaron en profundidad, de tal manera que dicho arte llegó, incluso, a servirles de instrumento introspectivo con el qué ahondar en sus conciencias.

De nuevo, Morris (1993) nos pone sobre aviso de manera concreta, acerca de quiénes fueron los poetas más influidos por el cine y afirma que el pequeño papel desempeñado por el cine en la poesía de Aleixandre y de Salinas muestra que éste los atrajo y los estimuló, pero que nunca llegó a alcanzar la hondura de emoción y la importancia temática que adquirió en la obra de Alberti, Cernuda y García Lorca.

Estos cinco poetas que cita Morris como ejemplo entre la totalidad de la Generación del 27, son los que vamos a estudiar sucintamente, con el ánimo de comprobar cómo el cine les sirvió para ampliar sus capacidades imaginativas y ver también de qué manera éste repercutió, directamente, en la literatura, pues los poetas asistieron a la contemplación de una realidad mucho menos encorsetada, de tal modo que la ficción era tomada por real, merced a una de las 
propiedades del cinema. De acuerdo con Bikandi-Mejías (1997) la impresión de realidad es más poderosa en el cine que en la literatura o en el teatro. Que el cine influyó en la literatura es un hecho, como se desprende de las expresiones de distintos investigadores, entre otros, la de Pérez Bowie (1996):

La literatura [...] hubo de verse necesariamente afectada por esa revolución que desencadenó el cine; y lo fue por partida doble: de un lado, sometiendo su mirada a un proceso de adecuación que le llevaría a focalizar la realidad de acuerdo con los nuevos mecanismos de percepción que aquel le proponía; y, de otro, en su calidad de testigo de su presente, constituyéndose en reflejo fiel del mismo y dando cuenta de los cambios que se producían ( $\mathrm{p}$. 131).

Lo mismo expresa Urrutia en el prólogo a la obra de Sánchez Noriega (2000), en el que manifiesta que el cine transformó, totalmente, la concepción de realidad y del mundo, y que este cambio afectó a la literatura tanto, y del tal modo, que se podría denominar a lo escrito después del cinema como post-literatura. Un ejemplo más de Morris (1993) nos afianza más en la idea que venimos exponiendo, de que la literatura se vio modificada gracias a la expansión imaginaria de los poetas, con la aparición del cine: "Las películas condicionaban a los poetas a esperar lo inesperado, a aceptar como normal lo sobrenatural (...), a observar las cosas o a la gente en contextos o asociaciones inhabituales" (p. 71).

Ampliadas las capacidades perceptivas de nuestros poetas hasta límites inverosímiles, la poesía se convirtió en receptora de la metamorfosis que la mente de los poetas había experimentado, y, así, los creadores comenzaron a verter una producción poética completamente nueva, rupturista, que se apartaba de modo sustancial de la tradición heredada de un tiempo anterior. Veamos ahora cada uno de los poetas citados.

\section{Vicente Aleixandre}

Se podría decir que Vicente Aleixandre se acerca al cine sin que éste le traspase; siente una gran atracción por el sétimo arte, pero procura mantenerlo a una distancia prudencial sin permitirle que lo envuelva totalmente en su influjo. "Esta ausencia de alusiones específicas al 
cine sugiere que Aleixandre refrenó, cuidadosamente, su interés por éste, que resulta evidente por su pertenencia como socio al Cineclub" (Morris, 1993, p. 91).

Él mismo reconoce su afición como espectador desde una edad temprana, en una carta que remite a Morris; asimismo declara que solamente tuvo conciencia de inspirarse en la visión cinematográfica para su poema Cinemática, inserto en su libro Ámbito (Morris, 1993). Para Sánchez Vidal (1993), esta composición ofrece algunas semejanzas con el expresionismo alemán, cuya popularidad consiguió sus cotas más altas con la película El gabinete del doctor Caligari, y Morris asegura que se trata del homenaje al cine mejor logrado, por parte de Aleixandre.

Encontramos, también, aromas del sétimo arte en su obra en prosa, escrita a finales de los veinte, en la que utiliza vocablos de moda, provenientes del lenguaje cinematográfico. Del mismo modo, se perciben en La destrucción o el amor las diversas perspectivas que Aleixandre nos muestra de un objeto, como si se tratara de las múltiples posibilidades con las que cuenta la cámara cinematográfica.

Por todo lo expuesto, nos atrevemos a afirmar que con la excepción de Cinemática, y según la teoría de Morris (1993), parece aventurado intentar relacionar a Aleixandre con el cine, más allá de su papel de espectador: "El crítico que aporte Cinemática como prueba del interés de Aleixandre por el cine y busque las repercusiones (...) en otros lugares de su poesía, corre el riesgo de ver (...) lo que él desea ver y no lo que hay en realidad" (p. 87).

\section{Pedro Salinas}

El caso de Salinas es similar al de Aleixandre; pero la influencia cinemática no fue tan profunda como para modificar su proceso creativo, en opinión de Sánchez Vidal (1993, p. 133): "Aunque el cine no parece haber alterado de forma sustancial el proceder literario de Pedro Salinas, su poesía no se mantiene al margen de su sugestión (...)"; sin embargo, sintió la atracción novedosa y rupturista del cine y su poesía se verá afectada por el influjo cinematográfico, pero éste actuará solamente en las capas más superficiales de su creación: 
“(...) el interés de Salinas por el cine radica, claramente, de manera obvia, en la superficie de su poesía" (Morris, 1993, p. 88).

Entre sus poemas con claras alusiones al nuevo medio de expresión está Cinematógrafo (1920), incluido en Seguro azar; en él la invención del cine es comparada con el génesis. En el mismo poemario encontramos Far West, un poema cuyo personaje central es una figura femenina: Mabel, la caballista quien cabalga cruzando el viento. El poeta reflexiona acerca de una de las propiedades del cine mediante la que se recuperan hechos y acontecimientos pasados y se logra que perduren en el presente. Enfatiza en el abismo que existe entre su posición como espectador y el viento que una vez sopló en un lugar remoto y ahora sobrevive en el celuloide (Morris, 1993).

Dentro de su obra existen algunos otros ejemplos en los que se aprecia que el impacto de los sucesos contemplados en la pantalla le sirvieron a este autor como motivo para articular pequeños mundos de admiración, unas veces referidos a la belleza y sofisticación del mundo femenino y, otras, a actores, entre los que se podría citar a Charles Chaplin.

\section{Rafael Alberti}

Para la presentación de Alberti y su relación con el cine, creemos en la efectividad de sus palabras: "Yo nací -irespetadme!- con el cine", pertenecientes a la composición Carta abierta, de su obra Cal y Canto, y de ellas se deduce que se siente parte integrante del llamado sétimo arte. Según Gubern (1999), las primeras evocaciones cinemáticas que encontramos en la obra de Alberti datan de 1925, en su libro titulado Marinero en tierra, específicamente, en su poema Verano. En él, el poeta vierte el entusiasmo y el asombro que había sentido al contemplar los filmes, presentados al aire libre durante aquellos veranos en Andalucía. En esta misma línea, compuso otros poemas, y en ellos sigue presente su perplejidad por la propiedad cinemática que desdibuja los límites de la realidad y la ficción: “Nueva York está en Cádiz o en el Puerto / Sevilla está en París, Islandia o Persia" rezan algunos de los versos de su poemario Cal y canto (Alberti, 1981, p. 94). 
La fascinación y la extrañeza de las primeras películas dieron paso a otras sensaciones más profundas y determinantes en la vida de Alberti; fue un filme soviético, El acorazado Potemkin, del cineasta Eisenstein, presenciado en Brujas, en 1932, el que le impulsa a afianzarse en su ideología política, después de contemplar el abuso de la fuerza dominante del ejército del zar. De nuevo, cuando acompaña a su admirado amigo Buñuel a Extremadura para rodar el documental Las Hurdes, sentirá algo similar, pero esta vez no se trata de una cinta de cine -caso de El acorazado Potemkin-, sino de algo real y palpable, al comprobar in situ la paupérrima situación en la que vive la sociedad de esta región extremeña: Según Morris (1993), Alberti comprobó, por sí mismo, los efectos del abandono social cuando él y su esposa, acompañaron a Buñuel a las Hurdes, un lugar atrasado y abandonado de Extremadura, mientras se rodaba su película.

Si el primer cine provocó en Alberti loas de admiración y encantamiento, y más tarde le sirvió para tomar posiciones y ahondar en su ideología política, también le ayudó a bucear en su interior y extraer de él un mayor potencial lírico, y es lo que ocurre con los poemas dedicados a los actores del cine mudo, los que, posteriormente, conformarían la obra Yo era un tonto y lo que he visto me ha hecho dos tontos. Estos poemas vieron la luz durante un momento cultural en el que el cine atraía, en gran medida, a los creadores de distintas ramas artísticas, como indican las palabras de García Jambrina (1999, p. 16): “Un contexto en el que se funden y confunden (...) la poesía y el cine (...), marcado por el encendido entusiasmo que muchos escritores, intelectuales y artistas sienten por el cine, y, muy especialmente, por los cómicos del cine mudo".

Este es un contexto propicio para que Alberti rinda homenaje a tres grandes cómicos del cine mudo: Chaplin, Lloyd y Keaton y para que les recite unas composiciones poéticas, en el intermedio de la sexta sesión del Cineclub, celebrada el 4 de mayo de 1929 en el cine Goya de Madrid, los cuales versaron sobre el cine cómico de los esos actores y de algún otro, cuya línea se mantenía dentro de unos parámetros similares (Morris, 1993).

García Jambrina (1999), por su lado, cita y nos remite a La Gaceta literaria del 15 de mayo, en la que pueden ser leídos todos los elogios que recibió la poesía recitada por Alberti, no sólo como obra poética, sino también por las capacidades interpretativas de las que el poeta 
hizo gala. Por tanto, Alberti no se conformó con crear unos versos en los que se celebraban los actos más o menos graciosos de las figuras del cine americano de la época, sino que hubo que estudiarlos y adentrarse en su psicología, comprender el lirismo de sus gestos y de su mímica, para después fundirse con ellos y ponerles una voz propia.

Además de la voz, se producen otros préstamos, por decirlo así, entre los actores y el poeta; éste parte de sus personajes, pero hace su versión de éstos, a la vez que vuelca sobre ellos todas las cuestiones relacionadas con su ideología política y social, con lo que se pone de manifiesto que Alberti ha incorporado, naturalmente, sus dramas e inquietudes personales de aquellos años.

De lo expuesto se desprende la íntima relación que el poeta mantuvo con el cine y lo que este nuevo medio de expresión significó para él, tanto en su vida personal como en la creativa. Aquí nos hemos referido, expresamente, a un número limitado de poemas, aunque su obra se nos presenta cuajada de motivos y alusiones cinemáticos; $\mathrm{y}$, precisamente, con una de sus alusiones -como hicimos al principio-, por considerar que define mejor que ninguna otra expresión lo que Alberti sintió por el cine, concluimos este apartado con uno de sus versos: “De este amor mío tan delicadamente idiota".

\section{Luis Cernuda}

Utrera (2002) comienza el libro Luis Cernuda. Recuerdo cinematográfico con esta frase: "Cernuda fue uno de los miembros de la Generación del 27 que se sintió cautivado por el mundo del celuloide" (p. 7), y un poco más adelante nos encontramos la siguiente: "Como tantos otros jóvenes literatos de la época, Luis Cernuda se sintió fascinado por el mundo de la pantalla y, más o menos, ocasionalmente, dejó su huella cinematográfica en algunos de sus escritos cuando no en cierta correspondencia con sus amigos; tal es el caso del epistolario dirigido a Higinio Capote"

Asimismo, en la obra citada hallamos una afirmación indicativa de que el propio autor reconoció que dos de sus poemas contenidos en Un río, un amor: Nevada y Sombras blancas 
habían sido inspirados en sendos filmes. En el primer caso se trataba de un filme mudo, visto en Toulouse y la idea la tomó de uno de sus rótulos; mientras que el segundo poema lo compuso, estimulados sus sentidos por el rumor del mar, en una película que vio en París: White Shadows in the South Seas (Sombras blancas en los mares del Sur). Gubern (1999) nos introduce en un terreno mucho más íntimo y personal al asegurar:

Tal vez el más afortunado de todos los poemas inspirados en películas se lo debamos a Luis Cernuda, un poeta solitario y atormentado por su homosexualidad -como René Crevel-, que encontró un refugio para sus fantasías privadas en las oscuras salas cinematográficas. El título que dio a su gran compilación poética de 1936 -La realidad y el deseo- fue casi un manifiesto, una declaración contra la ingrata realidad y a favor del apremiante deseo, que sólo en parte fue colmado por las fantasías cinematográficas (p. 110).

Todo apunta hacia una dirección unívoca, a la que se une también Morris (1993), que revela la relación peculiar de Cernuda con el cine, puesto que ve en él una manera de evasión como contrapunto a la frustrante realidad en la que se hallaba inmerso. Cernuda se debate entre dos mundos escindidos: el de los sueños y el de la realidad; su ensoñación se alimentaba de sus visitas al cine como espectador y se inspiraba, muchas veces, en los actores que se convertían en motivo principal de sus panegíricos cantos. Tal es el caso del tercer texto de su trilogía Égloga, Elegía, Oda, cuyo contenido es claramente alusivo tanto a las perfecciones físicas como a las espirituales de un actor cualquiera; aunque Utrera (2002) nos pone sobre aviso de que, en principio, esta oda iba a titularse Oda a George O'Brien.

Los apolíneos actores no sólo se constituyeron en motivo de inspiración, en la vida de Cernuda, sino que también los tomaba como referencia a la hora de seleccionar su vestimenta y aderezos personales. Nuevamente, remitimos a Utrera (2002), al epílogo con el que finaliza esta obra sobre Cernuda y su relación con el cine: "La actitud cernudiana ante la pantalla parece estar más próxima a los valores emocionales de un voyeurista que al proceder racionalista de un distanciado espectador. Su frase "El cine, siempre" acaso deba interpretarse bajo una doble significación: catálogo y figurín de donde tomó modelo y fábrica de sueños donde pudo vivir el deseo literariamente despierto" ( p. 28). 
Según Morris (1993), el tiempo que Cernuda pasó en las salas cinematográficas, le permitió evadirse de la situación política de España y soñar una vida propia, más acorde con sus anhelos, aunque al salir, el poeta, fuera ya de la ficción, se protegía en su férrea soledad. No obstante, y a pesar de ello, el cine significó tanto para Cernuda que se convirtió en instrumento con el que ahondó en su personalidad y se conoció a sí mismo.

\section{Federico García Lorca}

Antes de explorar la obra de este autor y extraer lo que en ella exista de referencia cinematográfica, introduciremos la idea que Buñuel (1982) tenía acerca del poeta granadino:

De todos los seres vivos que he conocido, Federico es el primero. No hablo ni de su teatro ni de su poesía, hablo de él. La obra maestra era él. Me parece, incluso, difícil encontrar alguien semejante. Ya se pusiera al piano para interpretar a Chopin, ya improvisara una pantomima o una breve escena teatral, era irresistible. Podía leer cualquier cosa, y la belleza brotaba siempre de sus labios. Tenía pasión, alegría juventud. Era como una llama (pp. 154-155).

Las palabras de Buñuel, íntimo amigo de García Lorca, son un claro exponente de que nos encontramos ante un genio, $\mathrm{y}$, precisamente, esa misma genialidad pudo ser la que le llevó a captar las ingentes posibilidades que del cine podían tomarse para aplicarlas a otras actividades creativas, según Gubern (1999, p. 102). "A la vista de las fotografías de su escenificación en la época parece detectarse la influencia de la fotografía y del cine soviéticos, ya ampliamente difundidos en España por aquella época (...). Estaba claro que la sensibilidad escénica de Lorca había sido contaminada por la estética fotográfica y cinematográfica y, desde luego, desde antes de 1930".

Para Morris (1993), la influencia que el cine ejerció en García Lorca está plasmada de manera obvia en toda su obra, y que las obras de este autor descubren la importancia de su relación con el cine: las escenas, la técnica, los actores y las formas de interpretación. Considera que sus obras y sus poemas incluyen personajes inspirados en las figuras estilizadas que había contemplado en las películas. 
El mismo Morris (1993), asegura que García Lorca declaró su gusto por el cine, de manera abierta, en distintas actividades culturales, y lo compara, en este sentido, con Alberti; así pues, se comprueba la atracción que este autor sintió por el cine y cómo éste actuó sobre su obra. Hemos de añadir que las huellas cinemáticas son múltiples y diversas, como lo afirma Utrera (1987), cuando dice que de forma ocasional, unas veces, anecdótica otras, García Lorca recurre a diversos elementos cinematográficos, presentes en el conjunto de su obra. Dentro de ese ámbito interdisciplinar en el que se desenvolvía García Lorca, hemos de hacer mención, en principio, a la quinta sesión del Cineclub, del mes de abril de 1929, en cuyo intermedio, entre una proyección cinematográfica y otra, recitó dos poemas: Oda a Salvador Dalí y Romance de Thamar y Amnón.

Concluida su tarea, se desplazó a Bilbao para llevar a cabo otras actividades culturales similares. Los poemas recitados abrieron ciertos interrogantes, ya que se esperaba la lectura de alguna pieza de inspiración cinematográfica, como por ejemplo El paseo de Buster Keaton. Sin embargo, esta elección no era casual, pues sobre esta composición el poeta había elaborado profundas elucubraciones, relacionadas con su peripecia vital, como demuestran las palabras de Morris (1993, p. 134): “Lorca utilizó a Keaton como máscara de sus propios miedos e inquietudes, y la lectura de esa obra habría supuesto una confesión pública de sus más profundos sentimientos, aunque lo hubiera expresado de forma indirecta o enigmática".

Por tanto, la figura de este actor cómico no sólo fue motivo de inspiración, sino que le sirvió como espejo en el que veía reflejada su imagen y se identificaba con él, especialmente en cuanto a que ambos padecían frustraciones provenientes de reglas sociales que reprimían su desarrollo personal. Este sentimiento de anhelo imposible lo va a verter el poeta granadino en su obra dramática Yerma, cuya protagonista vive con el gran deseo incumplido de ser madre, y en el personaje de La casa de Bernarda Alba, Adela, quien ansía un poco de libertad y estar fuera del dominio materno.

En otras piezas de teatro, también encontramos diversas referencias cinemáticas de las que citaremos unas pocas: en La zapatera prodigiosa, hay una escena que fue clasificada por el propio García Lorca como "casi una escena de cine"; el título Bodas de sangre está inspirado en una película histórica italiana Bodas sangrientas que se estrenó en España, en 1927; Rosita, el 
personaje principal de Doña Rosita la soltera, es comparada por el dramaturgo con la actriz italiana Francesca Bertini, en cuanto a un rasgo de excesivo sentimentalismo (Morris, 1993).

Asimismo, García Lorca sintió la atracción de las posibilidades creativas que la técnica cinematográfica poseía y se interesó por ella. Morris (1993): afirma que algunas de las acotaciones escénicas de este autor demuestran que, en efecto, sintió curiosidad por la técnica cinematográfica, y por los diversos movimientos y ritmos que un director de cine puede crear mediante trucos técnicos.

Esta atracción le llevó a trasladar varias técnicas a su obra literaria, y, así, en su poema titulado Tierra y luna, le imprime movilidad como un elemento activo. Por otro lado, en EI público sugiere que una cama gira alrededor de sí misma, para, a continuación, manifestar que la luz del escenario se torna plateada cual pantalla cinematográfica.

La estela cinemática en la obra de García Lorca va pareja con el sentir del autor y evoluciona en intensidad y en profundidad, en la misma medida en que él lo hace. Es al viajar a Nueva York cuando va a volcar toda su preocupación ante las situaciones sociales que contempla, en su poemario Poeta en Nueva York, como indica Gutiérrez Carbajo (1993): “En su obra poética, los recursos de carácter fílmico más evidentes son los que aparecen en Poeta en Nueva York. El doble plano de la naturaleza y de la ciudad que va contraponiendo en El rey de Harlem o la superposición de imágenes en Danza de la muerte o en La ciudad sin sueño, no son ajenos a las técnicas cinematográficas" (p. 148).

La mirada atenta del poeta, sensibilizado ante las desigualdades e injusticias que gran parte de la ciudadanía neoyorquina soportaba, tomó a esta población como fuente de inspiración. Según Morris (1993), los meses que pasó en esa ciudad constituyeron un estímulo y un sobresalto para su sensibilidad poética y su equilibrio emocional, y que las composiciones de Poeta en Nueva York son el resultado concreto de ese estímulo y la expresión del sentido de atrocidad de una ciudad que poseía, según él, todas las características del infierno en la Tierra.

El contenido de ese poemario presenta grandes similitudes con la visión que Fritz Lang ofrece de esta ciudad en su película Metrópolis. En ambas obras se nos muestra un ambiente urbano frío e inhóspito, poblado con dos tipos de seres: los poderosos o clase dominant, y los desasistidos y sin recursos de ningún tipo. Un ejemplo de los últimos lo encontramos tanto en la 
película de Lang -en la que los obreros trabajan en un subterráneo hasta su extenuación, con el fin de que la producción no disminuya- como en el poema La aurora de Poeta en Nueva York, en el cual sus protagonistas salen para ganarse el sustento antes del amanecer, deambulando como autómatas por los espacios deshumanizados de esa gran ciudad.

Y como colofón del interés suscitado por el cinematógrafo en García Lorca, tenemos la prueba más firme en su guión de cine Viaje a la Luna, escrito en la época de Poeta en Nueva York, con grandes afinidades entre ambos. En opinión de Monegal (1994), de esa experiencia viajera surgen Poeta en Nueva York, El público y Viaje a la luna, textos muy relacionados entre sí, los cuales no sólo tienen en común su origen, sino, también, muchos de sus temas y motivos.

Utrera (1987) confirma lo expresado por Monegal, al referirse al viaje que realizó Lorca a Nueva York. Afirma que allí comienza a escribir El público y los temas básicos Poeta en Nueva York. Considera que Viaje a la Luna se sitúa entre dos épocas de su producción poética: final del neopopularismo y comienzo de la etapa surrealista; es decir, la renovación.

Pareciera ser que la gestación de ese guión se llevó a cabo de manera fortuita y espontánea, según la opinión de diferentes estudiosos de este tema. Se ha escrito mucho acerca de cuáles podrían haber sido las fuentes de él; pero no ha sido posible llegar a una conclusión absoluta. Sobre esto, se barajan hipótesis, pero no dejan de ser simples especulaciones, las cuales no están basadas en datos objetivos. Independientemente de cuáles fueran las causas que llevaran a este autor a escribir ese guión, parece ser que su verdadera importancia estriba en que refleja, profundamente, un amplio espectro de la trayectoria vital del poeta de Fuente Vaqueros, como confirman las palabras de Morris (1993) cuando dice que el valor del guión de este autor estriba en el hecho de que fue escrito por un hombre complejo y un poeta sensible, preocupado por las relaciones humanas y los impulsos sexuales.

De lo expuesto se deduce que el texto Viaje a la Luna se encuadra en el período creativo de ese viaje físico y material que García Lorca realizó a la ciudad de Nueva York, y que este texto, junto a otros mencionados de la misma estética surrealista, es el resultado tanto de su incursión en la ciudad norteamericana como, también, de otro viaje de carácter interiorizante y espiritual, y todo ello salpicado por la influencia cinematográfica. 
En las primeras décadas del siglo XX, los poetas de la Generación del 27 fueron seducidos por el cine, como ya se ha dicho. Los dos primeros lo percibieron con menor intensidad y les afectó, únicamente, como espectadores. El trío restante se vio imbuido de su magia de tal manera que este nuevo medio de contar historias se convirtió en un elemento de introspección. El cine alimentó su imaginación y, gracias a él, sus temas, vivencias y técnicas se enriquecieron ampliamente, y no faltan voces que afirman que sin el cine su literatura habría sido menos moderna y menos cosmopolita.

\section{Conclusión}

El cine penetró en nuestro suelo en las primeras décadas del siglo XX no de manera aislada, sino acompañado de otros movimientos artísticos, propios de la modernidad. Hasta este momento, España se encontraba en un punto de estancamiento creativo, si bien se empezaba a percibir un nuevo aire procedente de Europa con las nuevas tendencias vanguardistas, que se instalaron en nuestro suelo y germinaron sin dificultad, pues una nueva generación, la del 27, buscaba romper con lo establecido, y ayudada por figuras de la literatura española tales como don Ramón Gómez de la Serna, Luis Buñuel, o el chileno Vicente Huidobro, el panorama poético experimentó una gran transformación. El cine, como se ha explicitado, no fue ajeno a dicho cambio, y los poetas de esta generación que nos ocupa beben del cine, con él enriquecen su poesía y, en algunos casos, lo toman como paradigma de introspección personal, como instrumento de análisis de sus propias trayectorias vitales.

\section{Referencias}

Alberti, R. (1981). Cal y canto, Madrid: Alianza.

Bikandi-Mejías, A. (1997). Galaxia textual: cine y literatura, "Tristana" (Galdós y Buñuel). Madrid: Pliegos. 
Buñuel, L. (1983). Mi último suspiro. (Memorias). Barcelona:Plaza y Janés.

García Jambrina, L. (Mar.-Abr., 1998). La elocuencia del cine mudo: cine y poesía en Rafael Alberti, Clarín, Año IV, N 20, s. p.

Gubern, R. (1999). Proyector de luna. La Generación del 27 y el cine. Barcelona: Anagrama.

Gutiérrez Carbajo, F. (1993). Literatura y cine. Madrid: UNED.

Monegal, A. (1994). Viaje a la luna. Valencia: Pre-textos.

Morris, C. B. (1993). La acogedora oscuridad. El cine y los escritores españoles (1920-1936). Córdoba: Filmoteca de Andalucía.

Pérez Bowie, J. A. (1996). Materiales para un sueño. En torno a la recepción del cine en España, 1896-1936. Salamanca: Cervantes.

Sánchez Noriega, J. L. (2000). De la literatura al cine. Teoría y análisis de la adaptación. Barcelona: Paidós Ibérica.

Sánchez Vidal, A. (1993). La Generación del 27 y el cine. Cuadernos Hispanoamericanos, № 514515, pp. $125-142$.

Utrera, R. (1987). Federico García Lorca. / Cine. El cine en su obra. Su obra en el cine. Sevilla: Asociación de Escritores Cinematográficos de Andalucía.

Utrera, R. (2002). Luis Cernuda. Recuerdo cinematográfico. Sevilla: Fundación El Monte. 